\title{
A Trial Implementation of Using Deuterium Oxide Dose-to-Mother and Dilution Technique Among Beninese Children: Challenge and Critical Points
}

\author{
Jaurès Hontongnon Felix Lokonon ${ }^{1}$, Waliou Bodounrin Ayanda Amoussa Hounkpatin 1, *, \\ Adama Diouf $^{2}$, Aubierge Joelle Flenon ${ }^{3}$, Félix Bodjrenou Sonon ${ }^{4}$, \\ Polycarpe Pierre Adechola Kayodé ${ }^{\text {, Nicole Idohou Dossou }}{ }^{2}$ \\ ${ }^{1}$ Department of Nutrition and Food Sciences, Faculty of Agronomics Sciences, University of Abomey-Calavi, Abomey-Calavi, Benin \\ ${ }^{2}$ Department of Animal Biology, Faculty of Sciences and Techniques, University Cheikh Anta Diop, Dakar, Senegal \\ ${ }^{3}$ Department of Monitoring, Evaluation \& Learning, Nutrition at the Center Project, Care International, Cotonou, Benin \\ ${ }^{4}$ Department of Maternal and Child Health, Ministry of Health, Cotonou, Benin
}

\section{Email address:}

amouswal@yahoo.fr(W. B. A. A. Hounkpatin), lokononjaures@yahoo.fr(J.H. F. Lokonon), adama.diouf@ucad.edu.sn(A.Diouf), Aubierge.Flenon@care.org(A.J. Flenon), felixsonon2000@yahoo.fr(F. B. Sonon),polykap@yahoo.fr(P. P. A. Kayodé), nicole.dossou@ucad.edu.sn(N. I. Dossou)

*Corresponding author

\section{To cite this article:}

Jaurès Hontongnon Felix Lokonon, Waliou Bodounrin Ayanda Amoussa Hounkpatin, Adama Diouf, Aubierge Joelle Flenon, Félix Bodjrenou Sonon, Polycarpe Pierre Adechola Kayodé, Nicole Idohou Dossou. A Trial Implementation of Using Deuterium Oxide Dose-to-Mother and Dilution Technique Among Beninese Children: Challenge and Critical Points. World Journal of Public Health.

Vol. 4, No. 2, 2019, pp. 34-42. doi: 10.11648/j.wjph.20190402.12

Received: April 24, 2019; Accepted: May 28, 2019; Published: June 12, 2019

\begin{abstract}
Within decade years, the deuterium dilution techniques are largely used in developing countries for breast milk output and body composition which are the important indicators of public health nutrition interventions. But the implementation of these techniques needs a familiarity with standard operating procedures. This paper presented the challenge met while using these stable isotope methods among Beninese children. The checking data and estimate of deuterium equilibration period were tested on 15 children aged 6-22 months for the body composition (BC) and 08 mother-child pairs having 5.5 months children aged for assessing breast milk intake (BMI). We have found that collecting saliva from 6 months children was very demanding. Children above 6 months aged chewed up the dentals swabs or cotton wool. Instead of cotton stalk, mother's index finger has been used to overcome saliva collection challenge. For BC measurement, some mothers got angry and left before the third saliva collection. Seven children have rejected the dose or vomited immediately after the dose administration. The plateau equilibration was between 2 and 3 hours. Concerning data quality, the Total Body Water percentage at 2, 2.5 and 3 hours were between $40-75 \%$ for 7 children. Only one over 8 children was less than $60 \mathrm{mg} / \mathrm{kg}$ of total error for BMI output. These results are crucial to conduct the large study. It showed precautions that might be taken into account in order assure high quality data about BMI output and children BC and therefore to improve the quality of the assessment public health actions.
\end{abstract}

Keywords: Deuterium Oxide, Fat Free Mass, Fat Mass, Breastmilk

\section{Introduction}

Nowadays, nutrition is crucial for the development actions in low-income countries including Benin. According to the Global Nutrition Report (2016), improved nutrition is the platform for progress in health, education, employment, female empowerment, and poverty and inequality reduction [1]. Thus, it is important to use the objective methods to really measure the progress and impact of nutritional interventions [2]. Isotopic methods can play an important 
role for achieving that goal. The assessment of breastfeeding practices and body composition are among many examples of applications of stable isotope techniques [3-4] which can contribute to the evidence base for improving stunting reduction programmes [5].

Indeed, recent studies revealed that the conventional methods of assessing Exclusive Breastfeeding practice (EBF) were biased [6]. Owino has showed that in many countries, the prevalence of EBF measured with mother's own recall are tended to be overestimated by about $40 \%$ at 3-6 months [4]. Alternative reference methods of the 24-hour recall to measure EBF practice is the deuterium oxide dose-to-mother.

Deuterium oxide dose-to-mother technique for the determination of breast milk intake and water from sources other than human milk, consist in administrating a dose of $30 \mathrm{~g}$ of deuterium oxide to the mother after collecting the saliva sample from the mother and her baby (baseline). Then, postdose samples were collected on day 1 , day 2 , day 3 , day 4 , day 13, and day 14 [7]. Regarding deuterium dilution technique for the measurement of body composition; it consists in the administration to the children, a dose of $0.5 \mathrm{~g} / \mathrm{kg}$ of body weight (dose for FTIR Shimadzu equipment), after having collected reference saliva sample [8]. After an equilibration time, about 3 hours for children and infant, two post-dose samples are collected. The physiological status of participants affects the water turnover of the children's bodies and therefore the equilibration time [8]. Age, health status, and climate also influence this turnover [8]. That's why, it is strongly recommended to carry out a pilot study prior to the implementation of this technique, in order to determine the interval in which post-dose saliva samples in local circumstances can be collected [8].

In Benin, it is planned an additional evaluation study of Nutrition at Center (N@C) Initiative implemented by CARE International Benin/Togo, which will use these two previous isotope techniques. That add-on study is part of the International Atomic Energy Agency (IAEA) Technical Cooperation Project INT6058 entitled "Contributing the evidence base to improve stunting reduction programs".

Recently, the use of dilution isotopic in children with moderate acute malnutrition and the methodological issues have been largely described by Fabiansen et al [9]. However and in context with children healthy apparently, our pilot study aims to:

1. Familiarize the local team to standard operating procedure (SOP) for saliva samples collections

2. Appreciate the equilibration period of the dose and the quality of outputs (Total Body Water and breast milk output quantity),

3. Propose alternatives to faced challenge for the success of add on study itself.

\section{Methods}

\subsection{Ethical Clearance}

Permission and ethical clearance have been received from
Benin National Ethics Committee for Health Research of Ministry of Health (CR $n^{\circ} 05$ from 26/01/2017 and $\mathrm{N}^{\circ} 15 / \mathrm{MS} / \mathrm{DC} / \mathrm{SGM} / \mathrm{DRFMT/CENRS/SA}$ on 07/04/2017). Locals politico-administrates authorities were informed and approved the study. Written informed consent of the enrolled children's parents was obtained after they received complete information about the study.

\subsection{Setting and Design Study}

From April to June 2017, a cross-sectional survey was conducted in Bonou, South-Benin. Bonou is one of the communes where $\mathrm{N} @ \mathrm{C}$ has been implemented. Indeed, the final add on study should be conducted at Dangbo, second commune of N@C. The main study of the research programme will target mothers who have children 4-5.5 months aged for the determination of breast milk intake (study 1) and monitor these children to 6 and 12 months for body composition study (study 2 ).

\subsection{Sample}

Determination of breast milk intake at 5.5 months: A sampling convenience of eight (08) mothers-children aged of 5.5 months was recruited within $\mathrm{N} @ \mathrm{C}$ Initiative beneficiaries. These women have freely accepted to participate in the pilot study.

Estimation of Total Body Water (TBW) in children aged 623 months: In addition to 08 children above, others seven (07) children aged between 7-23 months, have been recruited in the commune. Body composition was assessed in all 15 enrolled children aged 6-23 months, and exclusive breastfeeding was measured in 08 mother-child pairs aged 5.5 months. Finally fourteen (14) children were effectively included in the studies (Figure 1).

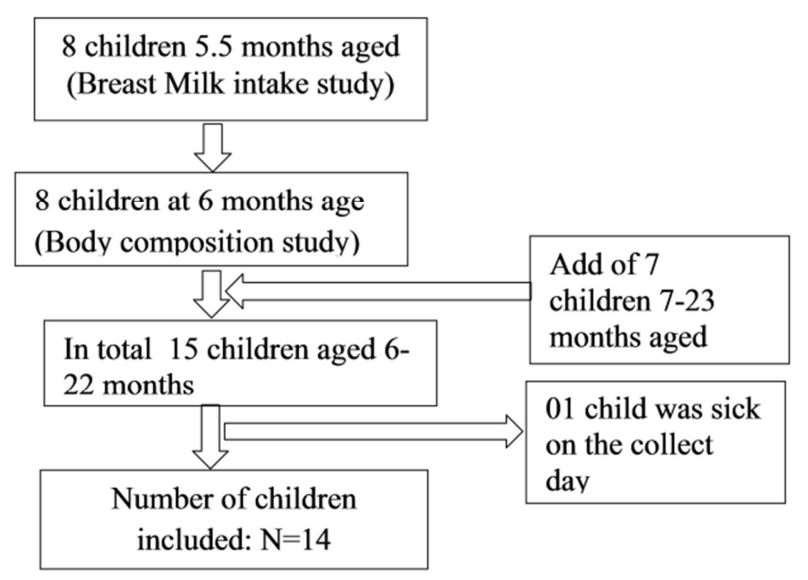

Figure 1. Sample size per study.

\subsection{Field Data for Breast Milk Intake Determination}

An accurately weighed dose of $30 \mathrm{~g}$ of deuterium oxide (99.8\% purity, Cambridge Isotope Laboratories Inc. Andover, MA, USA) was orally administered to the mother and container was doubly rinsed with drinking water [7]. Prior to dosing, the mother and child provided a pre-dose saliva 
sample $(\sim 4 \mathrm{~mL})$ into a clean, sterile and dry tube to determine the background or natural deuterium enrichment. The post-dose saliva samples were collected in cryogenic tubes from the mother and child on the 1st, 2nd, 3rd, 4th, 13th, and 14th days after dose administration to the mother
(Figure 2). Fourteen sample of saliva were collected and stored at $-20^{\circ} \mathrm{C}$ until analysis. Weight and height of mothers and children were collected on the day 0 and day 14 th. Samples transport to laboratory was done in cool box with dry ice package.

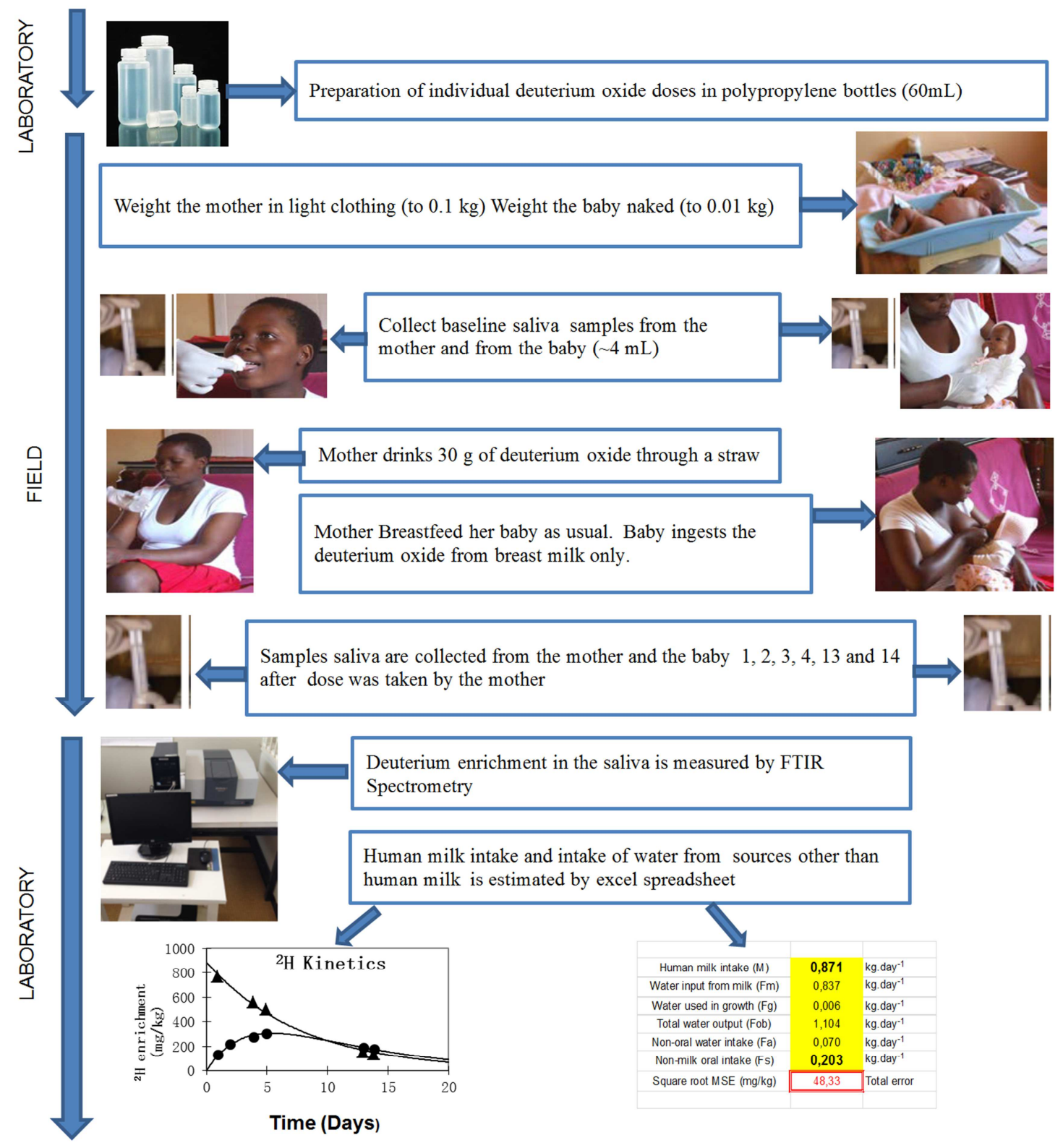

Figure 2. Summary of procedure for assessing human milk intake by deuterium oxide to mother technique, adapted from IAEA [7].

\subsection{Field Data for Assessment of Children Body Composition Aged Between 6 and 23 Months}

In the beginning of the study, child weight and height were measured and baseline saliva sample was collected. Then, a dose of $3 \mathrm{~g}$ (child weight less than $10 \mathrm{~kg}$ ) and $6 \mathrm{~g}$ (child weight more than $10 \mathrm{~kg}$ ) of deuterium oxide were respectively administered to children. Doses were prepared and administered using a dosing suitable syringe. We have introduced the feeding tube at the extremity of the syringes. This facilitates the entry of deuterium in children mouth. The precise dose consumed by child was measured by the difference in weight of filled syringe and empty syringe after dosing (Figure 3). Three saliva samples were collected after administration of dose ( $2 \mathrm{~h}, 2.5 \mathrm{~h}$, and $3 \mathrm{~h}$ after dose). Child weight and height were taken before and after study [8]. All anthropometric measures (study 1 and study 2) were also collected according to standard operating procedures and WHO's recommendations [7-8]. We have used an electronic balance accurate to $10 \mathrm{~g}$ for children (Type SECA 869; maximum $20 \mathrm{Kg}$ ) and to $0.1 \mathrm{~kg}$ for mothers (Type SECA 354, maximum $150 \mathrm{~kg}$ ). Mother height and infant length were determined using the ShorrBoard measured to the nearest $0.1 \mathrm{~cm}$. All measures were taken in triplicate. 


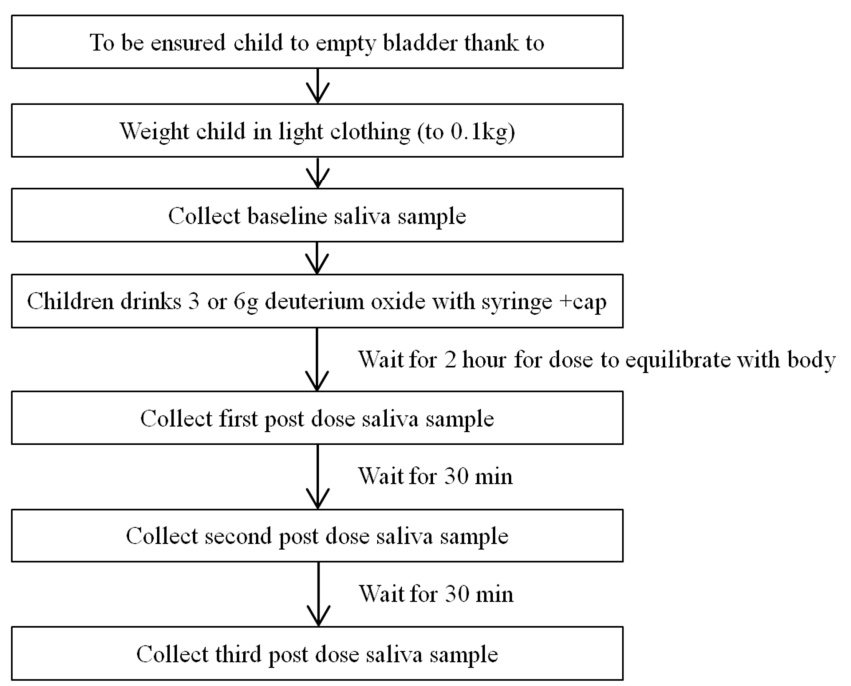

Figure 3. Flow chart describing the procedure for measuring total body water by deuterium dilution.

\subsection{Training of Research Team}

All fieldworkers had been trained on Standard Operating Procedures (SOP) for deuterium dilution technique to assess body composition and deuterium dose-to-the mother technique to assess breastfeeding practices in infants and young children $5.5-23$ months of age. At this training, all the SOP for dose preparation, collection of saliva samples, and dose administration, anthropometry were reviewed and tested on field.

\subsection{Implementation of Data Collection}

Two teams of five research assistants who followed the previous training have participated in the pilot study. Each team was organized in three work post presented in table 1 . The data have been collected in education/vaccination room located in the district health center. All mothers came to this place for different collect time.

Table 1. Organization of work post.

\begin{tabular}{|c|c|c|c|c|}
\hline \multicolumn{3}{|l|}{ Day 1} & \multirow{2}{*}{ Day $2,3,4,13$} & \multirow{2}{*}{ Day 14} \\
\hline Work post 1 & Work post 2 & Work post 3 & & \\
\hline \multicolumn{5}{|c|}{ Assessment of Exclusive Breastfeeding practices by mothers } \\
\hline $\begin{array}{l}\text { Reception of participants } \\
\text { Anthropometry }\end{array}$ & $\begin{array}{l}\text { Saliva collection Pre-dose from } \\
\text { mother and her baby }\end{array}$ & $\begin{array}{l}\text { Administration of the dose to } \\
\text { mothers }\end{array}$ & $\begin{array}{l}\text { Saliva Collection } \\
\text { Post dose }\end{array}$ & $\begin{array}{l}\text { Saliva Collection Post dose } \\
\text { Anthropometry }\end{array}$ \\
\hline \multicolumn{5}{|c|}{ Measurement of body composition in children } \\
\hline $\begin{array}{l}\text { Reception of participants } \\
\text { Anthropometry }\end{array}$ & $\begin{array}{l}\text { Saliva collection Pre-dose from } \\
\text { children } \\
\text { Saliva Collection Post dose }\end{array}$ & $\begin{array}{l}\text { Administration of the dose to child } \\
\text { Administration of questionnaire }\end{array}$ & & \\
\hline
\end{tabular}

\subsection{Analysis of Saliva Enrichment by FTIR}

All deuterium enrichment saliva was measured using Fourier Transform Infrared Spectro- photometer (FTIR, Shimadzu IR Prestige 21 Vienna, Austria) at Integrated Struggle against Malaria Center (CLIP) of Faculty of Health Sciences, Cotonou, Benin. The accuracy of deuterium analysis over the range of enrichments likely to be encountered has been checked using gravimetrically prepared standards.

\subsubsection{Preparation of Calibration Standard}

Nine standards of $100 \mathrm{~mL}$ were prepared by diluting 99.8 atom $\%$ deuterium oxide with local drinking water in a volumetric flask and weighed on an analytical scale following SOP described by IAEA [8]. The enrichment was ranged from 0 (natural abundance drinking water) to 2000 $\mathrm{mg} / \mathrm{kg}$; an enrichment above that likely to be encountered in saliva samples. To prepare the standard calibration, a solution of $\sim 1000 \mathrm{mg} / \mathrm{kg}$ (ppm) was prepared by weighing 99.8 atom $\%$ deuterium oxide $\left(\mathrm{D}_{2} \mathrm{O}\right)$ and diluted in normal drinking water from the laboratory.

\subsubsection{Calculation of Standards Enrichment and Standard Curve by FTIR}

The standards Enrichments have been calculated following the formula (1)

$$
\text { Enrichment of } \mathrm{D}_{2} \mathrm{O} \text { in calibration standard }=\mathrm{A} /(\mathrm{B}-\mathrm{A}) \times 10^{6} \mathrm{mg} / \mathrm{L}(\mathrm{kg})
$$

Where

A: Weight of $\mathrm{D}_{2} \mathrm{O}$

$\mathrm{B}$ : Weight of drinking water $+\mathrm{D}_{2} \mathrm{O}$ in $1 \mathrm{~L}$ flask and

$\mathrm{B}-\mathrm{A}$ : Weight of added drinking water.

From the values of calculated enrichment and measured enrichment to FTIR, standards curves of FTIR (2) were obtained and appreciated.

$$
\mathrm{Y}=\mathrm{aX}+\mathrm{b}
$$

Where $\mathrm{a}=$ gradient and $\mathrm{b}=$ intercept
The gradient a $>0.95$ and the intercept between -0.5 and + $20(+20>b>-0.5)$ were the indicators of good accuracy [8]. To appreciate the precision, we have used background (water enrichment) which must be between -10 and $+10 \mathrm{ppm}$ and the coefficient of variation $[\mathrm{CV}=(\mathrm{SD} / \mathrm{mean}) \mathrm{x} 100]$ of standard. CV should be less than $1 \%$.

\subsection{Data Analysis}

Field data were reported in the appropriate papers forms then the data was entered in the Epidata 3.1. Field and 
laboratory data were compiled by two differences assistants. The checking was performed and mainly errors were minimized. The data of breast milk intake was especially entry to the Excel 2007 program "Human Milk calcs" which helped to calculate intake milk by children and a water intake from sources other than breast milk by children

\subsubsection{Calculation of Total Body Water (TBW)}

TBW was calculated from the volume of distribution $\left(V_{D}\right)$ of a $D_{2} \mathrm{O} . \mathrm{V}_{\mathrm{D}}$ was calculated from the enrichment of ${ }_{2} \mathrm{H}$ in body water and the dose of $\mathrm{D}_{2} \mathrm{O}$ consumed.

$$
\mathrm{V}_{\mathrm{D}}(\mathrm{kg})=\text { dose }(\mathrm{mg}) / \text { enrichment }(\mathrm{mg} / \mathrm{kg})(3)
$$

Adjusted for exchange of hydrogen atoms in tissues: TBW $(\mathrm{kg})=\mathrm{V}_{\mathrm{D}} / 1.04[10-13]$.

\subsubsection{Appreciation of Equilibration Period (Plateau)}

Only the children who had the 3 samples of saliva post dose were used. The mean enrichment at $2 \mathrm{~h}, 2.5 \mathrm{~h}$, and $3 \mathrm{~h}$ was calculated and a curve of plateau equilibration was set out. According to Wong et al, the time equilibration was defined as the earliest time point when consecutive enrichment values became $<2 \%$ different from the previous hour [14].

\subsubsection{Quality Control for Determination of Breast Milk Intake}

The human milk intake by breastfed infants was calculated using Excel spreadsheet as described by Slater following the guidance notes on data evaluation [15].

\subsubsection{Total Body Water and Quality Control}

Quality control followed the steps described above:

1. Reproducibility of TBW: The Coefficient of Variation of Total Body Water measurements must be $<3 \%$.

2. $\% \mathrm{TBW}$ normal range must be between 40 and $75 \%$ of body weight

\subsubsection{Statistics}

Only descriptive statistics was conducted (mean, standard deviation, coefficient of variation, percentage) with SPSS v21.

\section{Results}

\subsection{Challenge While Collecting Saliva}

It's important to highlight that the collection of saliva samples with children over 6 months is doable but extremely difficult. It happened that we took until $1 \mathrm{~h}$ before collecting $2 \mathrm{ml}$ of saliva. The standard technique of saliva collection by moving the swab around the baby's mouth until the cotton wool is sodden [7-8, 16] were not practicable for many infants having teeth. In fact, these infants chewed up the dentals swabs or cotton wool. Instead of cotton stalk, we have proposed to use the index finger of mothers around which we rolled up the cotton. This new approach allowed having in less than one hour, $2 \mathrm{ml}$ saliva samples because the mothers were already using this technique to clean their children's mouths every morning.

In the body composition measurement, we had four mothers who were angry and stopped study before the third saliva collect. It was difficult to collect the three post-dose saliva samples due to the time of saliva sample collect. For some children, pre-dose and the first two post-dose collection times were so long going up $4 \mathrm{~h}$ that mothers became impatient and decided to stop the study. It was important to report also that after the equilibration time about 2 hours later, and given the time taken by the reference saliva collect, children were tired and cried incessantly. This increased the impatience of mothers and would make more difficult the cooperation of the mother for continuing the study.

\subsection{Challenge While Administration Dose to Infants}

During the dose administration, seven children rejected the dose or vomited immediately after the administration either $50 \%$ of the initial sample. The duration of saliva pre-dose collection is essential for the success of dose administration to a child. In fact, we observed that the more saliva collection pre-dose time was long, the more children refused to take the dose and hardly open their mouths. The calm and patience of fieldworker in charge to give the dose was also a factor contributing to success the operation.

\subsection{Challenge During Equilibration Time or Delay of Study for Participants}

Keeping children during the equilibration period without eating anything was a challenge for the collect teams. Each team member supported the mother of children during this time. Children just cried an about hour after dose administration. In these conditions, it was impossible not to breastfeed or feed them. We had 5 children $(35 \%)$ who drunk or took something between after dose administrating and saliva collection first post-dose sample.

\subsection{Precision and Accuracy of FTIR (IR Prestige 21)}

Figure 4 showed the curves of calibration FTIR. Equation were $\mathrm{y}=0.98 \mathrm{x}$. So, $\mathrm{a}=0.98$ and $\mathrm{b}=0$ and the FTIR was accuracy. All, $\mathrm{CV}$ of triplicate measured standards were less than $1 \%(0.4 \% ; 0.3 \% ; 0.8 \%$ for First and second, second and third, first and third measured standard respectively). 


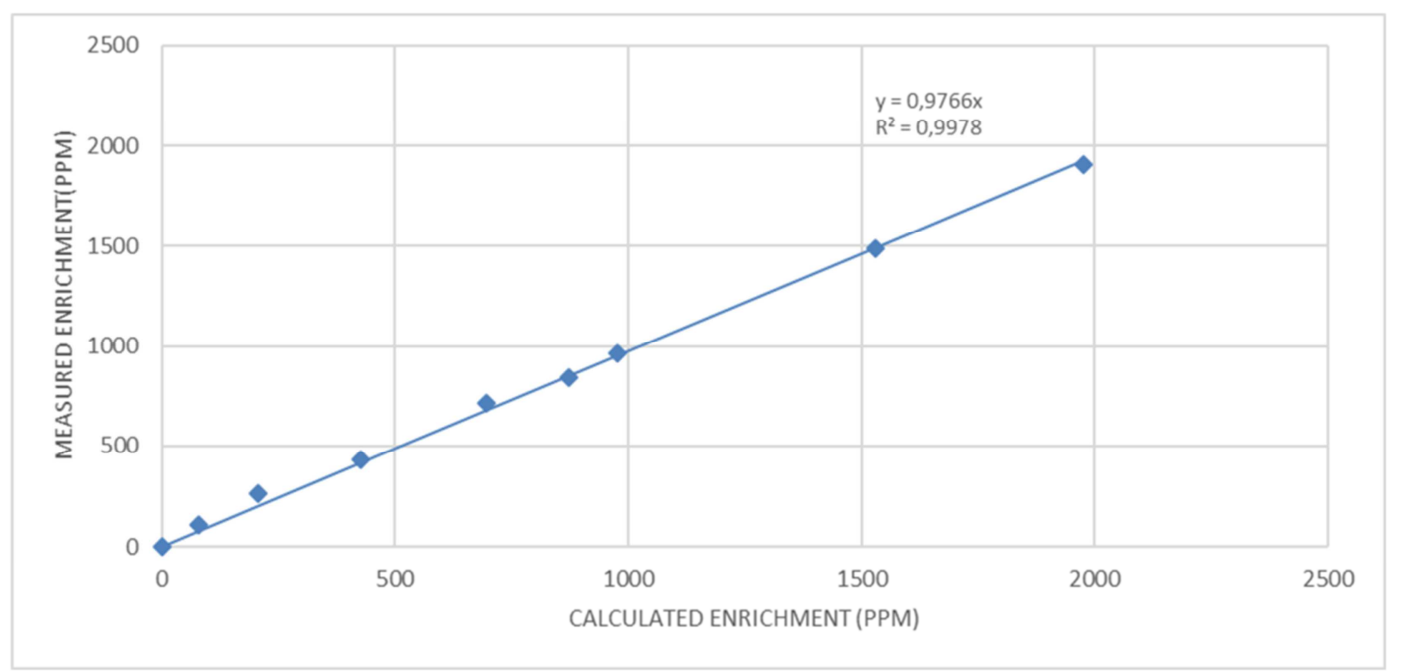

Figure 4. Curves of calibration of FTIR, Shimadzu, IR Prestige 21 Cotonou, Benin.

\subsection{Estimate of Breast Milk Intake and Control Quality}

After checking data of breast milk intake according to Slater [15], we noticed that only the total error of one child was less than $60 \mathrm{mg} / \mathrm{kg}$ (Table 2). Excluding this child, the mean of Human milk intake was $811.70 \pm 178.62 \mathrm{~g} / \mathrm{day}$.

Table 2. Breast milk intake and oral water intake from sources other than human milk.

\begin{tabular}{llll}
\hline ID & Non-milk oral intake (g/day) & Human milk intake (g/day) & Square root MSE (mg/kg) \\
\hline EP01 & 401.53 & 571 & 40.12 \\
EP02 & 926.76 & 1267.72 & $149.78 * *$ \\
EP04 & 368.80 & 751.58 & 18.96 \\
EP05 & 479.38 & 993.60 & 27.55 \\
EP09 & 123.00 & 629.27 & 47.03 \\
EP08 & 88.68 & 926.94 & 48.14 \\
EP07 & 48.01 & 776.47 & 53.75 \\
EP06 & 39.48 & 1033.08 & 47.91 \\
\hline
\end{tabular}

ID: Identifiying;*Value out range; MSE: Mean Square Error

\subsection{Equilibration Time (Plateau)}

Equilibration time was tested on 09 infants with whom we were able to collect three saliva post dose (2h, $2.5 \mathrm{~h}$ and $3 \mathrm{~h})$ samples. During the fieldwork, the real hours of saliva post dose collection were in average $2 \mathrm{~h} 10 \mathrm{~min}, 2 \mathrm{~h} 46 \mathrm{~min}$ and
$3 \mathrm{~h} 22 \mathrm{~min}$. The Figure 5 presents, the mean enrichment by real time after dose administration. Thus, the plateau equilibration was between $2 \mathrm{~h}$ and $3 \mathrm{~h}$. The difference of consecutive enrichments at $2 \mathrm{~h}, 2 \mathrm{~h} 30$ and $3 \mathrm{~h}$ were $1.8 \%$ and $14.3 \%$ respectively. Between $2 \mathrm{~h}$ and $3 \mathrm{~h}$, this difference was $18.2 \%$.

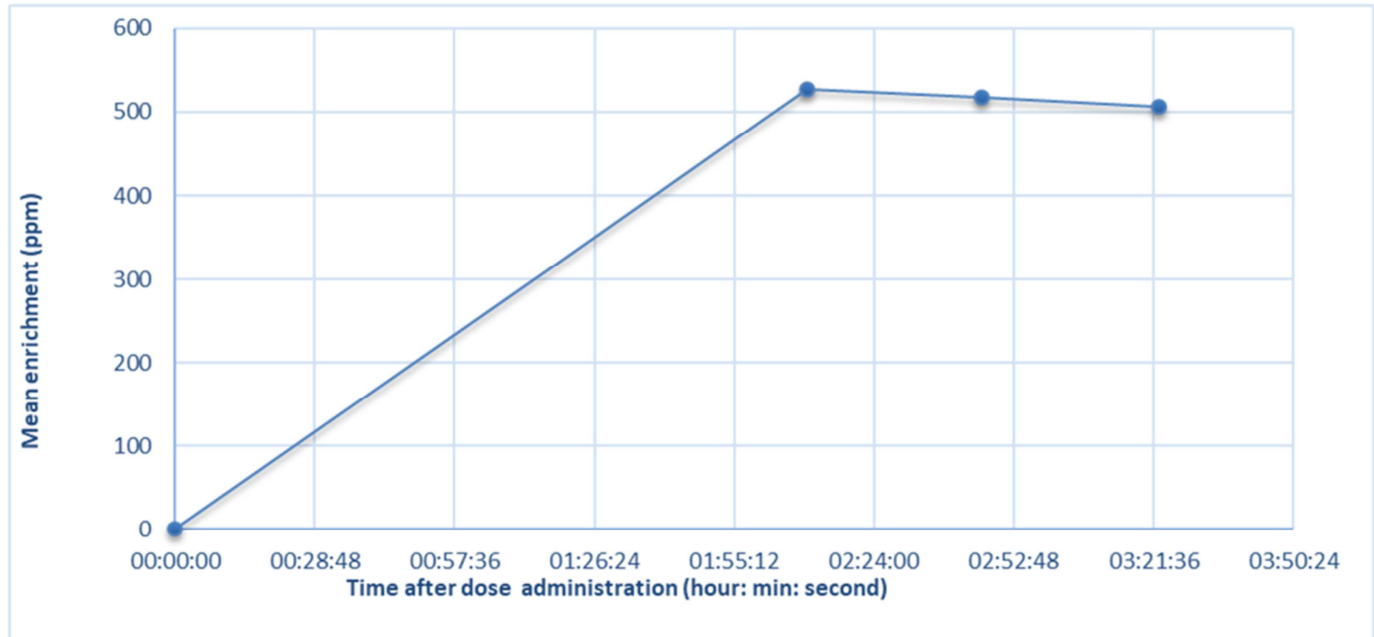

Figure 5. Equilibration of deuterium dose in children sampled. 


\subsection{Estimate of TBW and Control Quality of Body Composition Data}

Table 3 presents the TBW,\%TBW for 7 children who had taken total dose at $2 \mathrm{~h}, 2.5 \mathrm{~h}$, and $3 \mathrm{~h}$ and the CV of TBW between these hours.
$\mathrm{CV}$ of TBW measurements was $<3 \%$ for five $(05)$ children and one child for $2 \mathrm{~h}-2.5 \mathrm{~h}$ and $2.5 \mathrm{~h}-3 \mathrm{~h}$ respectively. Three (03) children had CV of TBW less than 3\% for consecutives measurements $2 \mathrm{~h}$ and $3 \mathrm{~h}$. The $\%$ TBW at $2 \mathrm{~h}, 2.5 \mathrm{~h}$, and $3 \mathrm{~h}$ almost were between $40-75 \%$ for all children (Table 3 ).

Table 3. Total Body Water $(T B W)$ at $2 h, 2.5 h$ and $3 h$, coefficient of variation between consecutive TBW and $\%$ TBW.

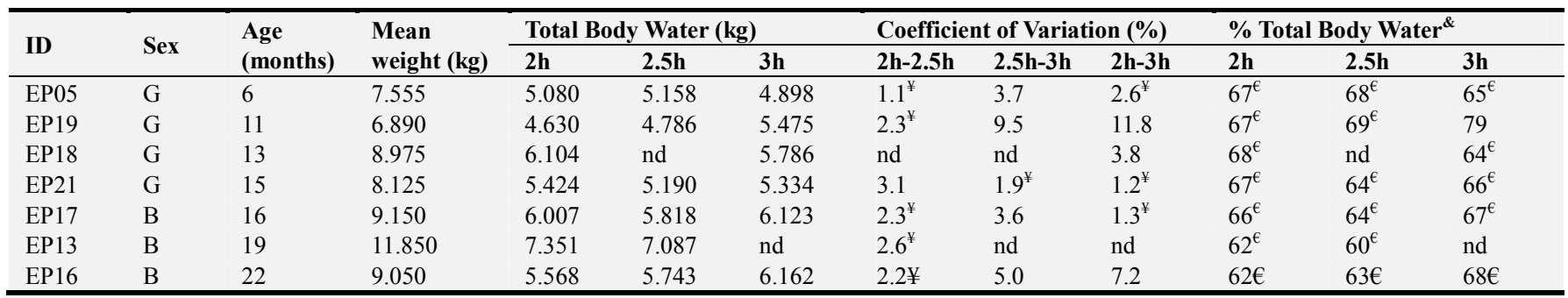

ID: identifying number; G: Girls; B: boys; ${ }^{*}$ values $<3 \%$; ${ }^{\epsilon}$ Values between $40-75 \% ;{ }^{\&}: \% \mathrm{TBW}=\mathrm{TBW} /$ body’s Weight

\section{Discussion}

In this study, we tested the use of two isotopic techniques, deuterium dose-to-mother for the assessment of exclusive breastfeeding and isotopic dilution deuterium among Beninese children for measurement of their body composition.

\subsection{Sample Saliva Collection}

We have found a real challenge in collecting saliva samples from children. It was reported by IAEA and Fabiansen [8-9] that collecting saliva samples was more difficult for children under 3 months old. In our pilot study, we found collection easier with children aged 5.5 to 6 months. For the over 6 months, winding the cotton swab in the mouth [16] was not possible for many of them. We have adopted a new method consisting to roll up cotton to the mother's index finger. That approach has facilitated the saliva collection. This technique could be recommended in the conditions where the mother's handwashing device (soap and drinking water) are available on study site.

\subsection{Administration of Child Dose}

We have got $50 \%$ of children who didn't fully consume the dose during administration. This high percentage could be explained by the stress of children due to anthropometric measurements and saliva pre-dose collection consecutively. In Burkina Faso, Fabiansen et al [9] had tested different strategies of dose administration in malnourished children. The dose had been diluted in juices such as Bissap Juice or water to facilitate the administration. They have observed that this technique was less successful than when the dose was given with water. In our study, we used the undiluted dose that was about $2.7 \mathrm{ml}$ or $5.4 \mathrm{ml}$ of deuterium. We believe that the administration of this small volume would be better given with the syringe + cap suggested by the IAEA [8].

\subsection{Equilibration Time and Duration of Collection}

We have found that the minimum time that mothers spent at the place of collect was $4 \mathrm{~h}$ for children who gave in less than 30 minutes, $2 \mathrm{ml}$ of saliva. This time can go up to 6 hours if the child didn't well salivate. It is desirable that the mothers sufficiently breastfed or properly fed their children at least 1 hour before starting collection. Because their children didn't quickly salivate during the pre-dose, the mothers became impatient. That influenced the post-dose collection especially post-dose at 3 hours and also the final anthropometric measurements. It will be better if the duration of collection does not exceed $4 \mathrm{~h}$. This leads to avoid stopping data collection by the mothers. So when mothers arrived on collection site at $7 \mathrm{am}$, they will complete body composition collection no later at $11 \mathrm{am}$.

The number of women, who have been included the day of collection, also had a negative influence on the process implementation. When the number of enrolled children exceeded 5 for a team of 5 fieldworkers, the collection management became problematic. The monitoring of children during equilibration period can be poorly performed. Thus, we would recommend for the collection of body composition data with (n) fieldworkers to enroll (n-1) children. One member is needed to manage time and monitor the entire process.

\subsection{Appreciation of FTIR Equipment}

The validity of the measurements also depends on the accuracy of the FTIR. We have seen that the calibration curve indicators were good to ensure validity of the measurements with locally available equipment (FTIR, IR prestige 21).

However, the non-comparison of the standard values with other laboratories could leave some shortcomings.

The equilibration period found was about $2 \mathrm{~h}-3 \mathrm{~h}$ range and is concordant with the current literature [17]. Post-doses can therefore be collected between this range. Like the duration of collection seems to reduce the quality of study or drop out 
of participants, our suggestion will support that the post dose collection starts at $2 \mathrm{~h}$. Given the general duration of saliva collection in our study area, the collection at 2.5 hours would often end around 3 hours after the dose.

\subsection{Precision Measurements of Human Milk Intake and Total Body Water}

Following the quality control approach for human milk intake, we observed that there is only one child whose sum of total errors was greater than $60 \mathrm{mg} / \mathrm{kg}$. This result justifies the good quality of the data sets when many cautions were taking during application of standards operating procedures by the collection team.

Concerning the measurement of total body water, we observed an increase of the percentage difference between the measurements of consecutive enrichments, especially after 2.5 hours. We suspect saliva quality after 2.5 hours because of the conditions under which his samples are taken like children crying or no mother's collaboration.

Facing difficulties to data collection for these techniques, future researches need to improve the methods of collect data on field. One advanced tools is Agilent technology FTIR which uses a little quantity of saliva (less than $1 \mathrm{ml}$ ). It is very easier to collect $1 \mathrm{ml}$ of saliva than $2 \mathrm{ml}$ and more in participants. In all, the participants of study must be informed correctly before starting the collect and fieldworks well trained.

\section{Conclusion}

Implementation of deuterium isotope stable technique dose-to-mother and dilution technique present challenge and are very demanding. Both techniques have same issues in saliva collecting from children. In dilution technique, children administration dose and period equilibration are critical steps for the study success. Fieldworkers training and large information of participants are necessary for the success of whole study. Therefore, that will improve the quality of evaluations of nutritional interventions.

This study suggests that the saliva collection could state at 2.5 hours instead of $3 \mathrm{~h}$ after dose as usually proposed. For the collection of body composition data, we would recommend with (n) fieldworkers to enroll (n-1) children. One member is needed to manage time and monitor the entire process. Our study confirms also that the equilibration time is between $2 \mathrm{~h}$ and $3 \mathrm{~h}$ among Beninese children. Otherwise, a new method consisting to roll up cotton to the mother's index finger, appear to be a practical way used to facilitate the saliva collection.

\section{Acknowledgements}

We would like to thank the mothers and infants who participated in the study, the health centre's staff, the nurses, the fieldworkers and the trainees (Jahdiel K., Rodrigue M., Berenice D., Yves S., Mariama I., Carrelle L., Anne D, Founkè K., and Valentine G.) for their support and contributions. We also like to thank Professor Kindé Gazard for facilitating access to the CLIP laboratory and International Atomic Energy Agency.

\section{References}

[1] International Food Policy Research Institute (2016). Global Nutrition Report 2016: From Promise to Impact: Ending Malnutrition by 2030. Washington, DC.

[2] International Atomic Energy Agency (2014). IAEA Bulletin 55-1-March 2014. http://www.iaea.org/bulletin (accessed July 2016).

[3] International Atomic Energy Agency (2017). Infant and young child nutrition. https://www.iaea.org/topics/infant-and-youngchild-nutrition. (accessed June 2018)

[4] Owino O. V., Slater C., Loechl U. C. (2017). Using stable isotope techniques in nutrition assessments and tracking of global targets post-2015. Conference on 'Nutrition dynamics in Africa: Opportunities and challenges for meeting the sustainable development goals. Proceedings of the Nutrition Society: 1-9.

[5] International Atomic Energy Agency (2017). Contributing to the evidence base to improve Stunting reduction programmes. https://www.iaea.org/projects/tc/int6058. (accessed June 2017)

[6] International Atomic Energy Agency (2016). IAEA recommends technique to improve Nutrition assessment in Africa. https://www.iaea.org/newscenter/news/iaearecommends-nuclear-techniques-to-improve-nutritionassessments-in-africa (accessed Sept 2018).

[7] International Atomic Energy Agency (2010). Stable Isotope Technique to Assess Intake of Human Milk in Breastfed Infants. IAEA Human Health Series No. 7. Vienna: IAEA. http://www-pub.iaea.org/MTCD/Publications/PDF/Pub1429 web.pdf (accessed July 2016)

[8] International Atomic Energy Agency (2009). Assessment of Body Composition and Total Energy Expenditure in Humans Using Stable Isotope Techniques. IAEA Human Health Series No. 3 Vienna. https://nucleus.iaea.org/HHW/Nutrition/ TotalEnergyExpenditure/index.html (accessed July 2016)

[9] Fabiansen C, Yaméogo CW, Devi S, Friis H, Kurpad A, et al. (2017). Deuterium dilution technique for body composition assessment: resolving methodological issues in children with moderate acute malnutrition. Isotopes in Environmental and Health Studies.

[10] Fomon SJ, Haschke F, Ziegler EE, al e (1982). Body composition of reference children from birth to age 10 years. Am J Clin Nutr 35: 1169-1175.

[11] Lohman TG (1992). Estimating body composition in children and the elderly; Advances in body composition assessment. Human Kinetics.

[12] Racette SB, Schoeller DA, Luke AH, et al (1994). Relative dilution spaces of $2 \mathrm{H}$ - and 18O-labeled water in humans. Am J Physiol-Endocrinal Metab 267: E585-E590.

[13] Wells JCK, Ritz P, Davies PSW, al; e (1998). Factors affecting the $2 \mathrm{H}$ to $18 \mathrm{O}$ dilution space ratio in infants. Pediatr Res 43 : $467-471$. 
[14] Wong WW, Cochran WJ, Klish WJ, et al (1988). In vivo isotope fractionation factors and the measurement of deuterium and oxygen-18 dilution spaces from plasma, urine, saliva, respiratory water vaporand carbon dioxide. Am J Clin Nutr 47: 1-6.

[15] Slater Christine (2014). Guidance notes on evaluation of data in the Excel spreadsheet to calculate human milk intake by breastfed infants. https://humanhealth.iaea.org/HHW/ Nutrition/MilkIntake/index.html. (Accessed July 2018).
[16] Slater Christine (2013). Instructions for assessing body composition in infants and young children using the deuterium dilution technique: CRP E4.30.28 Standard operating procedure for assessment of body composition in infants and young children using the deuterium dilution technique: Saliva sampling and dose administration. https://humanhealthiaeaorg/ HHW/Nutrition/MilkIntake/indexhtml (Accessed July 2018).

[17] Traver M. A. L., Martinez F. E., Ferriolli E., et al (2009). Deuterium Equilibrium Time in Saliva of Newborn Infants. J Pediatr Gastroenterol Nutr 48: 471-474. 